\title{
A Study about the 3S-based Great Ruins Monitoring and Early-warning System
}

\author{
WangXuefeng a , HuangZhongyuan ${ }^{\text {a }}$,LiGongli ${ }^{\text {a }}$, ZhaLi $^{\text {a }}$ \\ ${ }^{a}$ Beijing Re-Yuanmingyuan Company Limited , Beijing, China - ligongli@ thid.cn
}

\author{
Commission VI, WG VI/4
}

KEY WORDS: great ruins, stereoscopic cartographic satellite, GPS, GIS, remote sensing monitoring

\begin{abstract}
:
Large-scale urbanization construction and new countryside construction, frequent natural disasters, and natural corrosion pose severe threat to the great ruins. It is not uncommon that the cultural relics are damaged and great ruins are occupied. Now the ruins monitoring mainly adopt general monitoring data processing system which can not effectively exert management, display, excavation analysis and data sharing of the relics monitoring data. Meanwhile those general software systems require layout of large number of devices or apparatuses, but they are applied to small-scope relics monitoring only. Therefore, this paper proposes a method to make use of the stereoscopic cartographic satellite technology to improve and supplement the great ruins monitoring index system and combine GIS and GPS to establish a highly automatic, real-time and intelligent great ruins monitoring and early-warning system in order to realize collection, processing, updating, spatial visualization, analysis, distribution and sharing of the monitoring data, and provide scientific and effective data for the relics protection, scientific planning, reasonable development and sustainable utilization.
\end{abstract}

\section{Preface}

Great ruins mean a large area of cultural heritage that has important value and rich storage, and they are the important carrier of Chinese nation's brilliant culture and vivid witness of its long history. With the rapid economic development and population increase in our country as well as the increasingly intense urban and rural expansion, infrastructure construction, farmer production and life construction, tourist development and utilization, and cultural relics robbery, the great ruins protection work is facing tremendous pressure (Xin Guan, 2008).

Great ruins monitoring provides important support for the world cultural heritage protection and management in China. Across the country, the great ruins have such features as high number, massive area, large scope, and diversified type. Some of them are located far away while some of them are in the right center of busy street. They are inclined to be damaged for different causes, merely through common monitoring method can by no means exert an effective monitoring (Yun Chen, 2012). When applied to a large scope, the common inspection approach needs layout of a number of monitoring apparatuses or devices, which consumes not only time but also lots of labor force and materials (Xuemei Liao, 2008).

The remote sensing technology uses optical detector to detect the ground features' electromagnetic wave information to realize the detection and identification of the environmental ground features. As for great ruins, due to the significant difference between the cultural relics and surround environment, the reflected or radiated electromagnetic wave also differs. The difference is remotely sensed to form different images which can help to distinguish the ground features after interpretation (Yueping Nie, 2012). The satellite remote sensing technology can be used to make timely, direct and comprehensive monitoring on the body of ruins and ruin protection site as well as surrounding land use and building construction, reconstruction and reformation within the key protection zones and construction control areas, check the implementation of relics protection planning, and provide accurate and direct materials for the macro policy making and law enforcement of national heritage conservation administrative management authority (Yun Chen, 2012). At present, the remote sensing technology plays an important role in the great ruins monitoring. In 2012 the State Administration of Cultural Heritage started the first phase of "National Key Great Ruins Dynamic Monitoring with Satellite Remote Sensing Technology" during which altogether 11 great ruins were monitored with the technology. The second phase of the project began in 2011 and 15 great ruins were set under monitoring. In addition, in 2012 the State Administration of Cultural Heritage entrusted China Relic Information Consultation Centre to undertake the monitoring work for 13 great ruins including Changan Relic, and Sui-Tang Luoyang City Relic (Yun Chen, 2012).

The geographic information system is a technical system that collects, stores, manages, computes, analyzes, displays and describes the geographic distribution data related to the whole or part of the earth surface (including atmosphere) space (Lun $\mathrm{Wu}, 1996)$ under the support of computer hardware and software systems. GIS strengths can be used to manage (Zhongkui Dong, 2004; Jianyao Shi, 2008; Hongchao Chang, 2010) or monitor (Jing Sun, 2013) the basic space data and remote sensing monitoring data of cultural relics and ruins, and carry out spatial distribution characteristics analysis and thematic map visualization of the historical ruins (Xia Huijun, 2010; Xin Ge, 2013).

The global positioning system (GPS) can be adopted to establish great ruins GPS control network as the datum information library for the remote sensing images comparison, so as to enhance the great ruins monitoring accuracy and lay accurate spatial information basis for the development of great ruins monitoring, protection and management in the future. The GPS technology is gradually applied to the geological disaster (such as landslide) monitoring (Nan Zhang, 2013) (Li Wang, 2014) and terrain monitoring (Hongbin Zhu, 2003). Our country successfully launched Resource Satellite 3 on Jan. 9, 2012 which was the first satellite in China that could carry out stereoscopic mapping. The monitoring on the three-dimensional image data of different periods can help to find the abnormal change in the relics under monitoring. (Yuanyuan $\mathrm{Su}, 2013$ ) (Fengzuo Wang, 2013) combined the advantages of Resource Satellite 3 to exert three-dimensional spatial study about the geology and landform. Jing Li (2013), Dejiang Li (2013) et al conduct monitoring on the spatial area.

With the remote sensing monitoring technology as major technical support, the paper sets to construct a great ruins monitoring and early-warning system by combining GIS data management, spatial analysis means and GPS high-precision 
control in order to complete the management, dynamic updating and thematic analysis of the great ruins monitoring information, realize collection and analysis of regional great ruins change information, and provide scientific data guarantee for the great ruins monitoring and protection state evaluation. In addition, we also make proposal about using the three-dimensional imaging technique of stereoscopic cartographic satellite to improve the great ruins information monitoring capacity, and improve and supplement perfect the great ruins monitoring index system.

\section{Great ruins monitoring index system and approach \\ 2.1 Great ruins monitoring index system}

In accordance with the features of great ruins in our country such as high value, large number, wide distribution, and massive area, we establish and determine the great ruins monitoring index system to provide basis for the system construction contents.

The great ruins monitoring objects mainly include the body part, environment and behaviors. The body monitoring adopts the meaning in broad sense, including both the monitoring of damage characteristics on the great ruins such as crack, inclination and weathering and the monitoring of the microenvironment factors directly causing those damage characteristics such as temperature, humidity, wind speed, wind direction, vibration and foundation settlement. The environment monitoring is divided into two parts: monitoring of the local environment within the great ruins, and the monitoring of local environment outside and around the ruins. It means the monitoring of the climate, atmospheric quality, and geographical environment. The so-called behaviors mean the activities of people. The behaviors monitoring is to monitor the artificial damage and effect on the ruins.

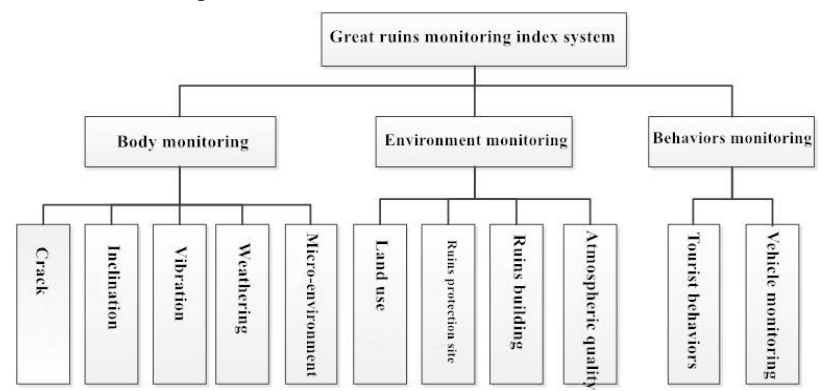

Fig. 1 Structure of monitoring index system

\subsection{Great ruins monitoring approach}

The monitoring approach can be divided into small-scale monitoring and large-scale monitoring in accordance with the spatial dimension of the monitored area.

(1) Small-scale monitoring usually employs advanced monitoring device and apparatus (such as inclinometer, vibroscope, level monitor, and micro-environment monitoring device, etc.) to realize the site monitoring. During the monitoring process, it is first necessary to design the monitoring position as per the ruins body, then install equipment to connect with the ruins body, next upload the data monitored by the device to the central server, and finally make use of the largescale server to store, manage, and analyze the monitored data. This approach is simple, direct and effective, but it requires direct installation at the body with high price cost.

(2) Large-scale monitoring adopts high-resolution and multi-time-phase satellite data or aeronautical data to monitor the change in ruins body, ruins protection site and surrounding land use within the key protection zone and construction control area.
During the monitoring process, it is necessary firstly to collect, correct, blend and inset the multi-time-phase image data in the monitored area to generate digital orthophoto, then classify and process the images, and finally compare and analyze the ruins body and ruins site in the monitoring area. The advantages of this approach are low price cost and high efficiency while the disadvantages include limited monitoring scale and accuracy.

Those two approaches have their own advantages, and they supplement each other during the practical monitoring. Therefore, it is necessary to combine them so as to exert effective monitoring and protection on the great ruins.

\section{Key technology in the great ruins monitoring}

The emphasis of the paper is laid on how to display the strengths of $3 \mathrm{~S}$ technology in the great ruins monitoring and early-warning system. The paper sets to make use of such strengths of geographic information system as spatial information visualization, storage and analysis to complete the great ruins fundamental database construction, sensor space management, monitoring data spatial analysis, and remote sensing monitoring data extraction. The satellite remote sensing technology is utilized to dynamically extract the abnormal change in the information about the ruins body and surrounding environment of different periods, while GPS is used to form GPS network in the great ruins area to improve the positioning accuracy of the basic space data and remote sensing monitoring data as well as the accuracy of the ruins information change monitoring.

\subsection{Stereoscopic monitoring data generation technology}

The stereoscopic monitoring data means the ruins monitoring data of three-dimensional information which result from the remote sensing data taken by the stereoscopic cartographic satellite after a series of remote sensing technology processing steps. The technology can be used to realize plane and stereoscopic monitoring of the great ruins body, ruins area, land use and surrounding environment.

The paper in the great ruins remote sensing monitoring makes use of Resource Satellite 3 as the major data source. The stereoscopic satellite data are processed to generate stereoscopic monitoring data (stereoscopic image map and slope map). The image shape and color change of the multi-time-phase stereoscopic monitoring data are analyzed in order to reflect the change in the ruins body, land use, terrain and ecological environment.

The stereoscopic monitoring technical process mainly includes four parts (as shown in the figure). Firstly, obtain the qualified stereoscopic image pairs in accordance with the ruins monitoring area; secondly, open respectively two stereoscopic images and choose the control points; thirdly adopt dense matching approach to process and generate digital surface model (DSM) and carry out filtering processing or artificial editing to generate DSM; and fourthly select overlapped digital orthophoto to form three-dimensional images and make slope computation towards the DEM to generate slope map.

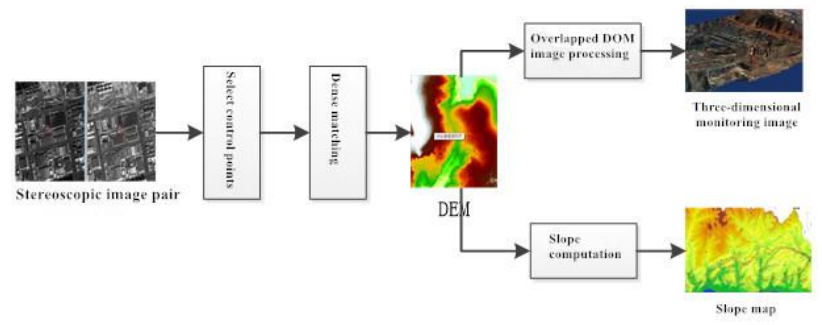

3.2 Multi-scale monitoring technology 
The multi-scale monitoring means to lay out all sorts of monitoring apparatus in small-scale area to monitor the ruins information while satellite remote sensing technology in largescale area. It employs those two monitoring means to realize integrated evaluation and analysis of the protection status-quo in the great ruins. The adoption of multi-scale monitoring technology can facilitate the selection of proper monitoring approach as per the features of the ruins body. Remote sensing monitoring can be selected when the ruins monitoring area is large but monitoring cost is limited, and the sensor monitoring can be selected when the area is small so as to ensure more reasonable ruins monitoring cost and more flexible monitoring system.

The technical process is composed of four parts (as shown in the following figure). Firstly, decompose and match the monitoring index system and correspond the monitoring indexes under different scales with different monitoring approaches, then set the monitoring cycle and choose proper monitoring cycle as per the ruins importance, next make integrated analysis of those two kinds of monitoring data, and finally generate monitoring or evaluation report with the monitoring data.

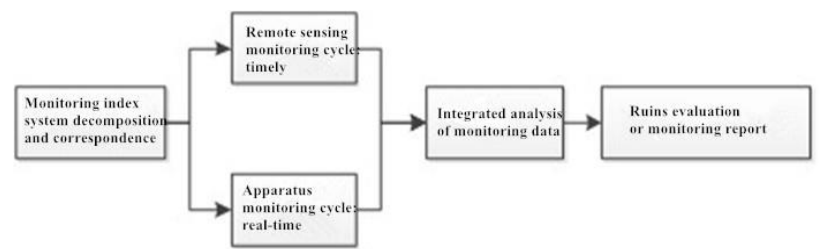

\subsection{High-precision GPS control network technology}

In order to solve the problem about deficient control materials in the great ruins, it is necessary to construct highprecision GPS control network so as to provide support for the ruins remote sensing data and fundamental geographical data.

The technical process includes four parts (as shown in following figure). Firstly, get to know the general information about the ruins area and design reasonable GPS control network distribution, then collect the on-the-spot GPS data, next process the GPS control network data, and finally transform the GPS data in the way of coordinate system.

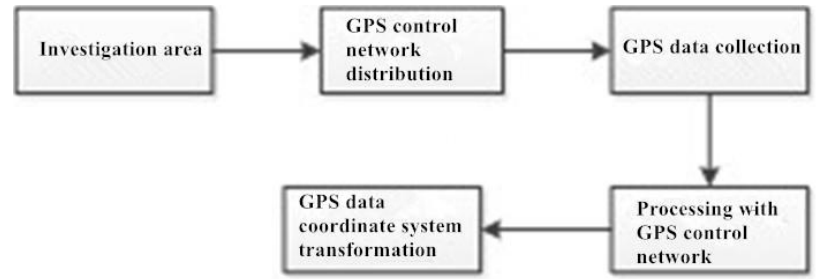

\subsection{Geographic information system technology}

The geographic information system technology is a core technology in the great ruins monitoring and early-warning system. Its spatial data management and digitalization capacities can be used to complete the investigation, exploration, surveying and digital image collection work, establish powerful fundamental database, and carry out spatial visual management with sensor. In addition, its powerful spatial analysis capacity can help to discover the rule of ruins monitoring data in space, while its map visualization capacity can realize thematic display of the ruins monitoring data and form ruins monitoring and protection evaluation thematic atlas.

This technical process is mainly formed by four parts (as shown in following figure). Firstly, make use of the geographic information collection software to complete the cultural heritage survey and investigation, surveying, digital image, sensor position information collection, then standardize the spatial database and import the data into the database system, next make statistical analysis of the spatial data, and connect the statistical results with the position, and finally form thematic map of ruins monitoring.

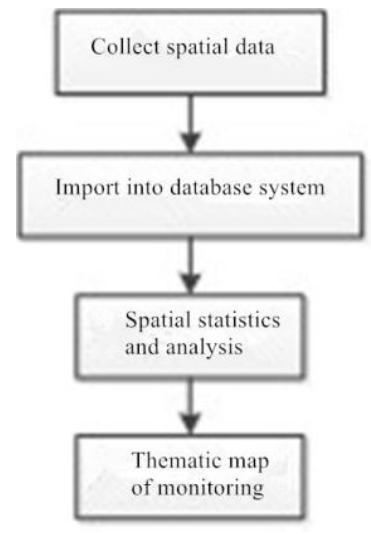

\section{Great ruins monitoring and early-warning system design} 4.1 System structure design

The great ruins monitoring and early-warning system is composed of the monitoring data source, data management information system, remote sensing monitoring information system, sensor monitoring information system, and monitoring data distribution and sharing system. Each subsystem plays an important role in the whole great ruins monitoring and earlywarning system. Among them, the monitoring data source includes satellite remote sensing data, GPS positioning data, and monitoring instrument data. The remote sensing monitoring information system and sensor monitoring information system carry out comparative analysis and statistical analysis through monitoring data source so as to timely find the risks in the ruins body and ruins site. The results of the monitoring analysis are stored, filed and copied by the data management information system, so as to ensure the safety and reliability of the monitoring data. The monitoring data distribution and sharing system is made use to distribute and share the ruins monitoring achievements maps and monitoring instrument data (Fig. 2).

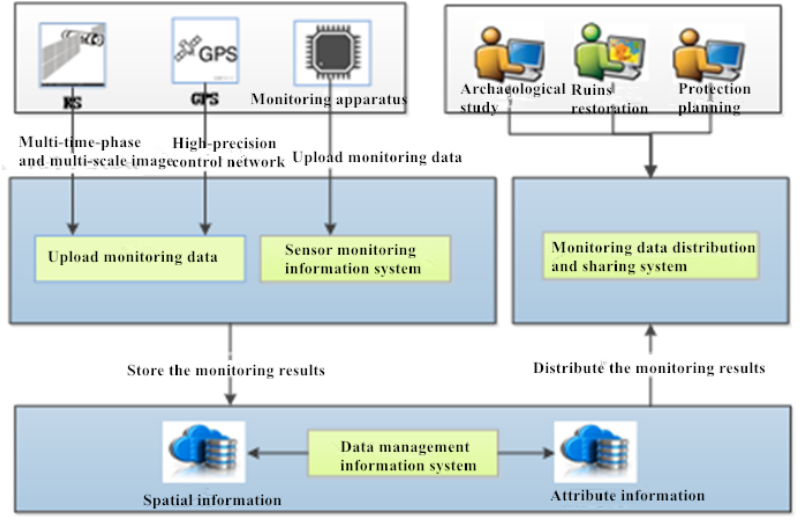

Fig. 2 Name

Sensor monitoring information system: this GIS-based system exerts effective monitoring on the ruins and relics from relics body, environment, remains component's spatial position, tourist state, and security conditions through intelligent monitoring devices configured with spatial position. It also makes use of the network technology to realize real-time transmission and storage of the collected data into the server database, and provide interface for related monitoring data, and such functions as inquiry and retrieval, statistical analysis, and monitoring report. 
Remote sensing monitoring information system: realize real-time collection, processing and updating of the spatial information as well as the present analysis of the dynamic monitoring process.

Monitoring data distribution and sharing system: distribute the monitoring results or data. The monitoring results include thematic map of spatial analysis, statistical statements and monitoring and evaluation data. Meanwhile, it provides outward service interface to meet the social public's requirement about taking part in the monitoring and scientific research institution's requirement about academic study. In addition, within the system there is also interface for the connection with national ruins monitoring center's system, so as to blend the great ruins monitoring standard system with national world cultural heritage standard system.

Data management information system: it can carry out user management, security certification, system log management, data backup, monitoring apparatus running supervision, and park management interface so as to guarantee the stable and reliable operation of the system and provide service support for the dynamic monitoring and early-warning.

Spatial database: it stores the basic spatial information, multi-time-phase satellite images or aerial images, and terrain analysis products (such slope map and aspect map).

Attribute database: it stores the sensor monitoring data as well as the ruins monitoring data statistics and analysis results.

\subsection{Technical process of the monitoring system}

\subsubsection{Business process of remote sensing monitoring system}

By referring to the coverage of the great ruins in protection planning, the paper suggests procuring the latest time-and-space high-resolution stereoscopic cartographic satellite remote sensing images which can not only provide plane information monitoring but also elevated information monitoring.

Draft latest time-and-space high-resolution color orthographic remote sensing images (or digital orthophoto map): set the remote sensing image of early stage as the mathematics foundation, combine with DEM data, and carry out such links as orthographic correction, data registration and blending, image inlaying, etc.

Extract digital elevation model (DEM): firstly input the stereoscopic image pairs, then define the ground control points and connection points, next define and extract DEM parameters, and finally carry out local artificial editing towards the output DEM results;

Compare the latest time-and-space satellite remote sensing images and DEM to compare with the early satellite images and DEM, conduct man-machine interactive multi-source information interpretation, accurately judge the changing elevation area, pattern spot, line-like ground object and ruins body, obtain the vector data of the changing ground object through screen digitalization, discover and interpret the changing ground object, and determine the change type and property.

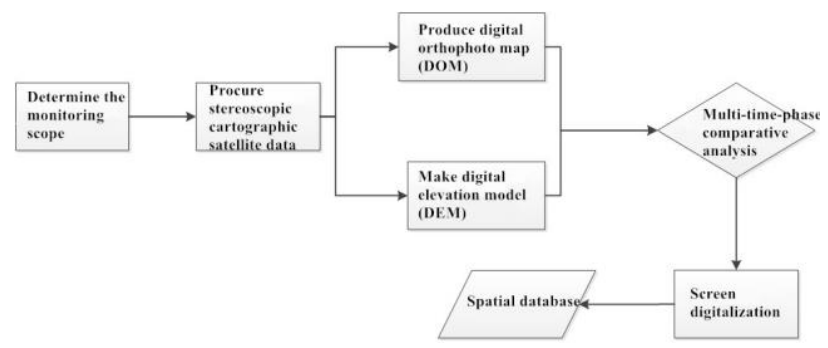

Fig. 3 Technical process of the remote sensing monitoring system

\subsubsection{Business process of sensor monitoring system}

The sensor monitoring system makes status-quo evaluation and analysis of the ruins area within the planned scope from status-quo investigation, environmental factors and artificial factors. By combining the status-quo of the ruins, the system choose proper monitoring device model, data transmission mode, and spatial layout to carry out site monitoring on the stone carving, ancient building, old trees, grotto, ancient ruins as well as the surrounding environment, climate, atmospheric quality, acid rain, noise, vibration, micro-environment, stability, wall temperature, weathering and ancient trees. The backstage server stores, analyzes, files and copies the transmitted monitoring data.

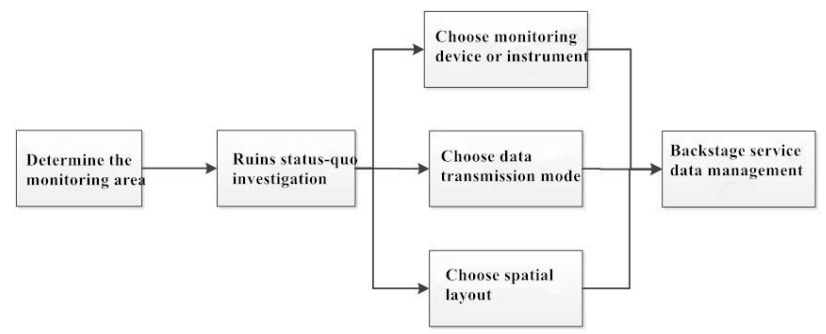

Fig. 4 Technical process of sensor monitoring system

\section{Conclusion and prospect}

Now the traditional great ruins monitoring index system and monitoring approach still have their disadvantages, such as high monitoring cost, difficult monitoring device layout, and limited monitoring scope. Therefore, the paper suggests making use of Resource Satellite 3 stereoscopic surveying data source as the data source for the remote sensing monitoring in order to enhance the three-dimensional monitoring in the relics information, and discover such geological disasters as collapse, landslide and debris flow. It is designed to make use of and integrate the remote sensing (RS), global positioning system (GPS) and geographic information system (GIS) in combination with the advanced information collection and communication technologies in the world to create a great ruins monitoring and early-warning system as well as provide important data source for the protection, scientific development and utilization of the ruins.

\section{References}

Xin Guan, Yalin Yan. [J] 2008 Brief discussion about the present great ruins protection. Jianghan Archaeology, 01: 129132

Yun Chen. [N] 2012 Discussion about great ruins remote sensing monitoring. China Cultural Relics News, 09-28007 Yun Chen. [N] 2012 Remote sensing monitoring of great ruins. China Cultural Relics News, 11-02007

Xuemei Liao. [D] 2008 Design of development of cultural relics environment monitoring data service system. Zhejiang University, 2008

Yueping Nie. [M] 2012 The application of remote sensing principles and approach in great ruins protection

Jing Li and Kexin Kou. [J] Feasibility study about the threedimensional change test based on Resource Satellite 3 data. Bulletin of Surveying and Mapping, 12: 31-35 
Jianyao Shi. [D] 2008 Design and realization of geographic information system in earthen ruins. Lanzhou University

Zhongkui Dong. [D] 2004 Establishment of geographic information system oriented at cultural relics. Tsinghua University

Hongchao Chang. [D] 2010 Design and realization of ruins and heritage data platform. Northwest University

Huijun Xia. [D] 2010 GIS-based study about the spatial distribution features of historical and cultural ruins. Xi'an University of Architecture and Technology, 2010

Jing Sun. [D] 2013 Study about the GIS-based Yuan Upper Capital ruins environmental protection monitoring and management system. Huazhong University of Science and Technology, 2013

Huijun Xia, Wudi Xu, and Yunying Ren. [J] 2010 Study about the spatial distribution features of GIS-based Yulin historical and cultural ruins

Journal of Yangtze University (Natural Science Edition) Science and Engineering Volume, 01: 293-295

Xin Ge. [D] 2013 Comparative study about the spatial distribution of ruins in Bohai and other historical periods. Yanbian University, 2013

Feng Mao, Wensheng Zhou, and Jianxi Huang. [J] 2008 Study about the application of spatial information technology in cultural heritage protection. Urban and Regional Planning Study, 03: 87-99

Nan Zhang. [D] 2013 Landslide deformation monitoring GPS carrier wave phase differential positioning and Kalman filtering algorithm study [D]. Harbin University of Commerce

Li Wang. [D] 2014 Study about high-precision GPS monitoring technology in geological disasters. Chang'an University

Hongbin Zhu, Xinxing Zhang and Ming Sun. [J] Test about the application of GPS technology in geological environment monitoring. Hydrological and Geological Engineering, 05: 6670

Yuanyuan Su, Jingfa Zhang, Wenliang Jiang, Hongbo Jiang, and Qiang Li. [A] 2013 Analysis of Daqingshan Mountain's front fracture structure, terrain and characteristics on the basis of Resource Satellite 3 (cartographic satellite DEM). Space-toground Observation Committee, Seismological Society of China 2013 Academic Seminar of Space-to-ground Observation Committee, Seismological Society of China. Collection of Abstracts. Space-to-ground Observation Committee, Seismological Society of China: 1

Fengzuo Wang. [D] Study about and realization of threedimensional geological GIS on the basis of images of Resource Satellite 3. Chang' an University
Jing Li and Kexin Kou. [J] Feasibility study about the threedimensional change test based on Resource Satellite 3 data. Bulletin of Surveying and Mapping, 12: 31-35

Dejiang Li, Lili Jiang and Bo Hong. [J] 2013 Application of Resource Satellite 3 data in the provincial body function zone monitoring. Geomatics \& Spatial Information Technology, 10: $50-52$ 